\title{
A Seasonal Approach for Analysis of Temporal Trends in Retail Marketing using Association Rule Mining
}

\author{
S. Hariharan \\ Research Scholar \\ SCSVMV University \\ Kanchipuram, Tamilnadu, India
}

\author{
M. Kannan \\ Assistant Professor \\ SCSVMV University \\ Kanchipuram, Tamilnadu, India
}

\author{
P. Raguraman,Ph.D \\ Assistant Professor \\ Sri Sankara Arts and Science \\ College, Kanchipuram, India
}

\begin{abstract}
In an era when the customer is deemed as the king of the retail market, it pays heed to analyze every dimension of the customer's purchase behavior to provide an insight into their buying patterns and to better understand retail rationale of the customers. This dissertation has attempted to envisage the temporal traits of the customer's behavior in the Retail marketing. The research has put forth a seasonal study on the association amongst products in the realms of Retail Industry. In a country like India, obsessed with diverse seasons, the companies need to come up with better seasonal strategies that drive the market. Seasons have various dimensions to it viz. climatic seasons, festival seasons, etc. For each of those seasons the target audience keeps changing and the association of a set of products with customers also changes. This dissertation carries out an empirical study on the impact of seasonal and socio-economic factors on the buying patterns of the customers using Data mining tools and specifically applying the association rule for the products sold in the retail market sector. The results were analyzed by segregating the dataset into three seasons namely, January-April, MayAugust, and September-December. The results were interpreted with relevance to the seasonal behavior of the customers defined by the association of products. Weka 3.7.9 data mining tool is used for analyzing the data collected from XYZ supermarket located in Kanchipuram, TamilNadu, India. A mammoth 12000 transaction dataset and 215 product categories were involved in the research. This study reveals threadbare about the temporal association of products, for the Retail market to capitalize upon and to establish a better understanding and to enhance their customer relationship.
\end{abstract}

\section{General Terms}

Association Rule Mining in Retail Marketing.

\section{Keywords}

Temporal Analysis, Retail Marketing Sector, Association Rule Mining.

\section{INTRODUCTION}

Retail marketing has been flourishing in the last decade and extensive work has been rendered in harnessing the power of data mining tools to unearth the buying patterns of the customers. There has been mushrooming of mega retail outlets in all major cities of India, trying to woe the customers. All these retail shopping malls want to have a competitive edge over their rivals and look for the assistance of computers and scientific ways to probe the purchase habits of the customers. There is also an increase in the spending index of the customers as even the rural India has set out on a shopping spree of late.
Various factors contribute to the dramatic increase in the purchase powers of the customers:

- Lifestyle changes of the Indian youth, who do not want to be disadvantaged in anyway and want to acquire all the latest that hits the market. The hefty salary package has also paved way for the affinity towards the spendthrift.

- Retail markets cashing in on the obsession of the people with seasonal spending. With so many religions in India each celebrating various festivals and functions of its own, customer has many innate reasons to buy.

- Urbanization of the small towns wherein the living standards of people has seen enormous sophistication leading to setting up of retail outlets. This has exposed many multinational brands to the rural society. In recent years, a lot of effort is invested in the area of retail market basket analysis, in the development of techniques to increase the interestingness of association rules.

\section{PROBLEM DEFINITION}

The purchase patterns of the customers are basically seasonoriented. The challenge is to track the association of retail products for every season. The retail market companies are engaged in this challenge to figure out what are the best products for a given season. Accomplishing this endeavour can help companies project the right products for the right season. Retail marketing has taken a new avatar in the form of e-shopping, where customers can call the shots sitting at the home and products delivered.

The problems that led to this investigative study are:

- The retail market companies do not have enough knowledge about the customer's choice of products.

- Retail market outlets couldn't envisage the seasonal products that the customer wishes to buy.

- Unpredictability of the customer's choice of product as the concept of the right-product is only transient in nature.

- Temporal mining is more important than Spatial mining in retail marketing.

\section{RESEARCH OBJECTIVES}

The objectives that stimulate the study are set as follows:

- Assess the existing literature on customer's seasonal behaviour in purchasing of retail products.

- To determine the association of products that strikes a chord with the customers and reasoning behind the association.

- To identify the products that connects well with the customers on a season-to-season basis.

- To suggest the factors that influences the association of certain products and with specific seasons. 


\section{RESEARCH QUESTIONS}

The following research questions were formulated:

$>$ What are the factors that influence customer's decision with respect to their buying patterns?

$>$ How to formulate a strategy for the companies to follow to get a competitive advantage over their rival in retail marketing?

$>$ Which factors contribute to the movement of specific products in a particular season? How important are the factors in the decision making process?

$>$ How factors such as cost of products, brand identity, customer loyalty to a brand have a bearing on product sales?

\section{UNIQUENESS OF THE RESEARCH}

$>$ The research is unique in the fact that it carries out an extensive research on temporal analysis of the association of products in Retail Marketing. There are many researches in the past focusing on the spatial mining, revealing the association of products with respect to a particular locality. But temporal mining is the first of its kind that is done in the field. The study is also appealing for the sheer quantity of the test data involved. As many as 215 product categories were considered for association and more than 12000 transaction datasets of the customers were used as test data. The enormity of the data played a vital role in improving the accuracy of the outcome of the study.

> The season-oriented study provides a way to better understand the seasonal behavior of the products in the market. The study would prove to a highly beneficial for the corporate by providing an altogether new dimension and perception to strategize their business prospects. This study should help them choose the right product to target the suitable customers. This gives a definite advantage for the companies over their rivals.

$>$ Once a rigorous seasonal study is done, it can be used up for ensuing years by the business people, as the seasonal interests of the customers seldom vary vastly and remain perpetual for at least few years down the line.. This is in contrast to the spatial mining which would diversify with different locations, warranting repeated mining to be carried out for each individual location. This implies that the overhead cost of analyzing the market will not recur frequently and thereby not burden the companies.

$>$ This research has explored exhaustively the various attributes of the term season. Apart from the literal meaning given to the season, socio-economic factors that bear an influence on the day-to-day life have also been accounted for analyzing a season. So this study doesn't delimit itself pertaining to the climatic seasons of the country.

\section{METHODOLOGY}

\subsection{Population}

A super market located in Kanchipuram of Tamilnadu was chosen as case study. The customers who purchased the products from the retail outlet were taken as the population for the study. Survey was targeted on transactions dataset that was spread over one year

\subsection{Procedure}

To have a thorough study of the association among products, transaction dataset spanning over at least one year was required. So a sum of 15000 transactions was collected from a super market featuring over 200 product types. Over 200 transactions with missing values were deleted. Due to the enormity of the number of transaction dataset it was decided to split it up into three seasons to provide a fine-grained mining of association of products. The collected data was converted into a suitable form for the application of association rule in data mining tool WEKA.

\subsection{Measure}

WEKA allows the resulting rules to be sorted according to different metrics such as confidence, leverage, and lift and conviction.

\subsubsection{Confidence}

This metric signifies the probability for two or more products being purchased together. The possible values range from 0 to 1. Values closer to 1 indicate higher probability and stronger association among the products [1].

\subsubsection{Lift}

Given a rule $\mathrm{L} \Rightarrow>\mathrm{R}$, lift [1] is the ratio of the probability that $\mathrm{L}$ and $\mathrm{R}$ occur together to the multiple of the two individual probabilities for $\mathrm{L}$ and $\mathrm{R}$, i.e.,

$$
\text { lift }=\operatorname{Pr}(L, R) / \operatorname{Pr}(L) \cdot \operatorname{Pr}(R) .
$$

If this value is 1 , then $\mathrm{L}$ and $\mathrm{R}$ are independent. The higher this value, the more likely that the existence of $\mathrm{L}$ and $\mathrm{R}$ together in a transaction is not just a random occurrence, but because of some relationship between them.

\subsubsection{Leverage}

Leverage[2] measures the difference between the probability of co-occurrence of $\mathrm{L}$ and $\mathrm{R}$ as the independent probabilities of each of $\mathrm{L}$ and $\mathrm{R}$, i.e.,

$$
\text { leverage }=\operatorname{Pr}(L, R)-\operatorname{Pr}(L) \cdot \operatorname{Pr}(R) .
$$

In other words, leverage measures the proportion of additional cases covered by both $\mathrm{L}$ and $\mathrm{R}$ above those expected if $\mathrm{L}$ and $\mathrm{R}$ were independent of each other. Thus, for leverage, values above 0 are desirable

\subsubsection{Conviction}

Conviction is similar to lift, but it measures the effect of the right-hand-side not being true. It also inverts the ratio. So, conviction[2] is measured as:

$$
\text { conviction }=\operatorname{Pr}(L) \cdot \operatorname{Pr}(\text { not } R) / \operatorname{Pr}(L, R) \text {. }
$$

\section{DATA ANALYSIS-INTERPRETATION}

\subsubsection{Analysis for the Season January to April}

The dataset for the season January to April was examined using the association law and the following 10 association rules were derived using the WEKA tool.

Best rules found using WEKA Tool:

1. $\mathrm{CHOCOLATES}=\mathrm{t}$ VEGETABLES $=\mathrm{t}$ MASALA ITEMS $=$ t $787==>$ RASNA_POWDER_JUICES $=\mathrm{t}$ 722

2. MOSQUITO_KILLERS $=\mathrm{t}$ CHOCOLATES $=\mathrm{t}$

MASALA_ITEMS $=\mathrm{t} 759==>$ RASNA_POWDER_JUICES $=\mathrm{t} 695$

3. MOSQUITO_KILLERS $=\mathrm{t}$ VEGETABLES $=\mathrm{t}$ MASALA ITEMS $=t 770==>$ RASNA_POWDER_JUICES $=t 705$

4. $\mathrm{CHOCOLATES}=\mathrm{t} \quad$ MASALA_ITEMS $=\mathrm{t}$ FLOUR_ITEMS $=t \quad 815 \quad==>\quad$ RASNA POWDER_JUICES=t 746

5. CLEANING_SOAPS $=t$ MASALA_ITEMS $=\mathrm{t} 852 \Rightarrow$ RASNA_POWDER_JUICES=t 777 
6. $\mathrm{CHOCOLATES}=\mathrm{t}$ VEGETABLES $=\mathrm{t}$ FLOUR_ITEMS $=\mathrm{t}$ $796==>$ RASNA_POWDER_JUICES $=\mathrm{t} 724$

7. MOSQUITO_KILLERS $=t$ CHOCOLATES $=\mathrm{t}$ FLOUR ITEMS $=\mathrm{t} 771==>$ RASNA_POWDER_JUICES $=\mathrm{t} 700$

8. VEGETABLES $=t$ MASALA_ITEMS $=t$ FLOUR_ITEMS $=\mathrm{t} 834==>$ RASNA_POWDER_JUICES $=\mathrm{t} 757$

9. CHOCOLATES $=t$ MASALA_ITEMS $=t 952==>$ RASNA POWDER JUICES $=\mathrm{t} 864$

10.VEGETABLES=t MASALA_ITEMS=t $968==>$ RASNA_ POWDER_JUICES=t 876

- 10 best association rules were derived. From the study of the association rules from transaction dataset for the season January to April, it can be seen that there exists a strong affinity of the following interesting products with Rasna powder and other juice items for the given season.

1. Chocolates

2. Vegetables

3. Cleaning soaps

4. Masala items

5. Flour items

6. Mosquito Killers

Table 1. Association Metrics For The Season January To April

\begin{tabular}{|c|c|c|c|c|}
\hline Rules & Confidence & Lift & Leverage & Conviction \\
\hline Rule 1 & 0.92 & 1.27 & 0.03 & 3.33 \\
\hline Rule 2 & 0.92 & 1.27 & 0.03 & 3.26 \\
\hline Rule 3 & 0.92 & 1.27 & 0.03 & 3.26 \\
\hline Rule 4 & 0.92 & 1.27 & 0.03 & 3.25 \\
\hline Rule 5 & 0.91 & 1.27 & 0.03 & 3.25 \\
\hline Rule 6 & 0.91 & 1.26 & 0.03 & 3.05 \\
\hline Rule 7 & 0.91 & 1.26 & 0.03 & 2.99 \\
\hline Rule 8 & 0.91 & 1.26 & 0.04 & 2.99 \\
\hline Rule 9 & 0.91 & 1.26 & 0.04 & 2.99 \\
\hline Rule 10 & 0.9 & 1.26 & 0.04 & 2.91 \\
\hline
\end{tabular}

The above table depicts the values for the four metrics (confidence, lift, leverage and conviction) used for evaluating the association of products for the season January to April.

1. The confidence value greater than 0.90 for 10 rules implies that more than $90 \%$ of customers buying Chocolates, Vegetables, Cleaning, soaps, Masala items, Flour items and Mosquito Killers are certain to buy Rasna and Juice items.

2. The lift values greater than 1.25 implies that the interesting products are closely knit together and their occurrences are highly dependent on the Rasna and Juice itmes 3. The leverage value closer to 0 clearly indicates that probability of occurrences of interesting products independent of Rasna and Juice items is almost null.

4. The conviction value greater than 3 indicates that one in three transactions containing the interesting products also contain Juice items.

\subsubsection{Interpretation}

The span of this season coincides with the summer season for the country. The hot and humid months of the calendar year have an influence on the customers inclined to buy more Juice items. The reasoning behind the customer's purchase of liquid items in the form of Rasna, Cool drinks and other juices is quite obvious, given the territorial harsh weather and oppressive nature of the season that prevail in the March and April months. The other items that were selling well were chocolates, as parents were willing to spend more for children on the summer holidays.

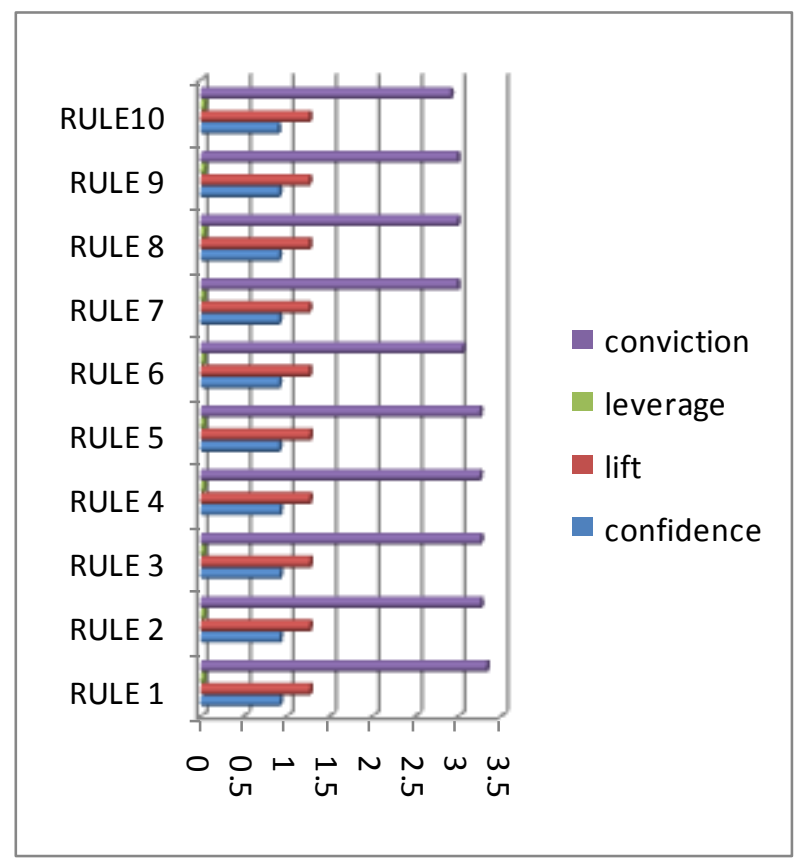

Fig 1: Association Metrics Chart for the Season January to April

\subsubsection{Analysis for the Season May to August: \\ Best rules found using WEKA Tool:}

1. $C L E A N I N G \_S O A P S=t$ CANDLES $=\mathrm{t} \quad$ RICE_FLOUR $=\mathrm{t}$ $786==>$ MASALA ITEMS $=\mathrm{t} 721$

2. INSTANT_COOKING_ITEMS $=$ t CLEANING_SOAPS = $\mathrm{t}$ RICE_FLOUR $=\mathrm{t} 757==>$ MASALA_ITEMS $=\mathrm{t} 693$

3. INSTANT_COOKING_ITEMS $=\mathrm{t}$ CANDLES $=\mathrm{t}$ RICE FLOUR $=t 768==>$ MASALA_ITEMS $=t 703$

4. CLEANING SOAPS $=\mathrm{t}$ RICE FLOUR $=\mathrm{t}$ TOOTH BRUSHES $=t 812==>$ MASALA_ITEMS $=t 743$

5. VEGETABLES $=$ t RICE FLOUR=t total=high $852==>$ MASALA_ITEMS $=\mathrm{t} 777$

6. CLEANING_SOAPS $=\mathrm{t}$ CANDLES $=\mathrm{t}$ TOOTHBRUSHES $=\mathrm{t} 795=\Rightarrow$ MASALA_ITEMS $=\mathrm{t} 723$

7. INSTANT_COOKING_ITEMS $=\mathrm{t}$ CLEANING_SOAPS $=\mathrm{t} \quad$ TOOTHBRUSHES $=\mathrm{t} \quad 769==>$ MASALA_ITEMS $=\mathrm{t}$ 698

8. CLEANING_SOAPS $=\mathrm{t}$ RICE_FLOUR $=\mathrm{t} 951==>$ MASALA_ITEMS $=t 863$

9. $\mathrm{CANDLES}=\mathrm{t}$ RICE $\mathrm{FLOUR}=\mathrm{t}$ TOOTHBRUSHES $=\mathrm{t}$ $832=\Rightarrow$ MASALA_ITEMS $=\mathrm{t} 755$

10. $C A N D L E S=t$ RICE_FLOUR $=t 967 \Rightarrow$ MASALA ITEMS $=\mathrm{t} 875$

- 10 best association rules were derived. From the study of the association rules from transaction dataset for the season May to August, it can be seen that there exists a strong affinity of the following interesting products with Masala Items for the given season.

1. CLEANING SOAPS

2. CANDLES

3. RICE_FLOUR 
4. TOOTHBRUSHES

5. INSTANT_COOKING_ITEMS

Table 2. Association Metrics for the Season May to August

\begin{tabular}{|c|c|c|c|c|}
\hline Rules & Confidence & Lift & Leverage & Conviction \\
\hline Rule 1 & 0.92 & 1.27 & 0.03 & 3.33 \\
\hline Rule 2 & 0.92 & 1.27 & 0.03 & 3.26 \\
\hline Rule 3 & 0.92 & 1.27 & 0.03 & 3.26 \\
\hline Rule 4 & 0.92 & 1.27 & 0.03 & 3.25 \\
\hline Rule 5 & 0.91 & 1.27 & 0.03 & 3.25 \\
\hline Rule 6 & 0.91 & 1.26 & 0.03 & 3.05 \\
\hline Rule 7 & 0.91 & 1.26 & 0.03 & 2.99 \\
\hline Rule 8 & 0.91 & 1.26 & 0.04 & 2.99 \\
\hline Rule 9 & 0.91 & 1.26 & 0.04 & 2.99 \\
\hline Rule 10 & 0.9 & 1.26 & 0.04 & 2.91 \\
\hline
\end{tabular}

The table and chart depicts the values for the four metrics (confidence, lift, leverage and conviction) used for evaluating the association of products for the season January to April.

1. The confidence value greater than 0.90 for 10 rules implies that more than $90 \%$ of customers opting for cleaning_soaps, candles, rice_flour, toothbrushes, instant_cooking_items are certain to spend for Masala Items.

2. The lift values greater than 1.25 implies that the interesting products are highly dependent closely knit together and their occurrences are highly dependent on the occurrence of Masala items.

3. The leverage value closer to 0 is an ample indication that the independence of interesting products and Masala items are almost negligible.

4. The conviction metric indicates that the customers wishing not to buy masala items invariably choose not to buy the interesting products of the season.

\subsubsection{Interpretation}

In this season stretching from May to August, masala items seems to find favour with the customers. As the season marks the festival fervor, the customers show interest in preparating of spicy foods and go for the masala items more than other seasons.

The peculiar item of interest to the customers in the season is Candles. This comes close on the heels of frequent power cuts and load shedding by Electricity board. The customers have been severly hit by the power problem and has been the reasoning behind the movement of the candles in the retail market.

The fast food culture seems to have caught up with the customers. Many are looking for instant cooking items as a quick-fix solution of their fast paced life style. Customers perceive the instant cooking items as a ready-made solution to lessen their work and time of preparation.

The other products to have an impact on the customers in this season are rice flours, tooth brushes and cleaning soaps.

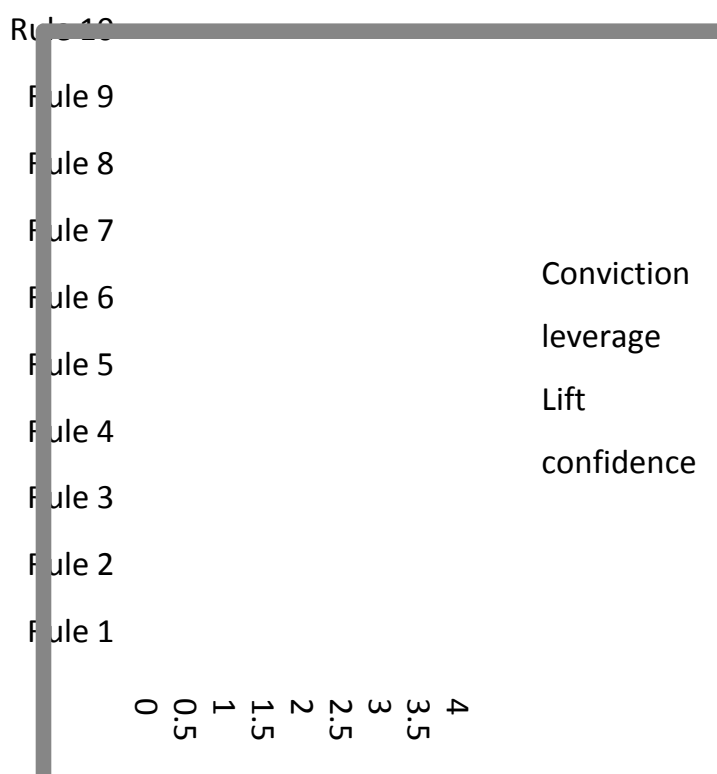

Fig 2: Association Metrics Chart for the Season May to August

\subsubsection{Analysis for the Season September to December:}

Best rules found using WEKA Tool:

1. CLEANING_SOAPS $=\mathrm{t}$ CANDLES $=\mathrm{t}$ TOOTHPASTE POWDERS $=\mathrm{t} 783==>$ MOSQUITO_KILLERS $=\mathrm{t} 718$

2. BATHING_SOAPS $=\mathrm{t}$ CLEANING_SOAPS $=\mathrm{t}$ TOOTHPASTE_POWDERS=t $753==>$ MOSQUITO_ KILLERS $=t 690$

3. $C L E A N I N G \_S O A P S=t$ TOOTHPASTE_POWDERS $=\mathrm{t}$ TOOTHBRUSHES $=\mathrm{t} 808==>$ MOSQUITO_KILLERS $=\mathrm{t} 740$

4. BATHING_SOAPS $=\mathrm{t}$ CANDLES $=\mathrm{t}$ TOOTHPASTE POWDERS $=\mathrm{t} 765==>$ MOSQUITO_KILLERS $=\mathrm{t} 700$

5. $S H A M P O O S=t$ TOOTHPASTE_POWDERS $=t \quad 849==>$ MOSQUITO_KILLERS $=\mathrm{t} 774$

6. $C L E A N I N G \_S O A P S=t$ CANDLES $=t$ TOOTHBRUSHES $=\mathrm{t} 793==>$ MOSQUITO_KILLERS $=\mathrm{t} 721$

7. BATHING_SOAPS $=\mathrm{t}$ CLEANING_SOAPS $=\mathrm{t}$ TOOTHBRUSHES $=\mathrm{t} 766==>$ MOSQUITO_KILLERS $=\mathrm{t} 696$

8. CLEANING_SOAPS $=\mathrm{t}$ TOOTHPASTE_POWDERS $=\mathrm{t}$ $946==>$ MOSQUITO_KILLERS $=$ t 859

9. $\mathrm{CANDLES}=\mathrm{t}$ TOOTHPASTE POWDERS $=\mathrm{t}$ TOOTHBRUSHES $=\mathrm{t} 830==>$ MOSQUITO_KILLERS $=\mathrm{t} 753$

10. $B A T H I N G \_S O A P S=t$ TOOTHPASTE_POWDERS $=\mathrm{t}$ TOOTHBRUSHES $=\mathrm{t} 825==>$ MOSQUITO_KILLERS $=\mathrm{t} 747$

- 10 best association rules were derived. From the study of the association rules from transaction dataset for the season September to December, it can be seen that there exists a strong affinity of the following interesting products with Mosquito Killers for the given season.

1. CLEANING_SOAPS

2. CANDLES

3. TOOTH BRUSHES AND TOOTH PASTE

4. BATHING SOAPS

5. SHAMPOOS 
Table 3 Association Metrics for the Season September to December

\begin{tabular}{|c|c|c|c|c|}
\hline Rules & Confidence & Lift & Leverage & Conviction \\
\hline Rule 1 & 0.92 & 1.27 & 0.03 & 3.32 \\
\hline Rule 2 & 0.92 & 1.27 & 0.03 & 3.3 \\
\hline Rule 3 & 0.92 & 1.27 & 0.03 & 3.28 \\
\hline Rule 4 & 0.92 & 1.27 & 0.03 & 3.25 \\
\hline Rule 5 & 0.91 & 1.27 & 0.04 & 3.13 \\
\hline Rule 6 & 0.91 & 1.27 & 0.04 & 3.13 \\
\hline Rule 7 & 0.91 & 1.26 & 0.03 & 3.02 \\
\hline Rule 8 & 0.91 & 1.26 & 0.03 & 3.01 \\
\hline Rule 9 & 0.91 & 1.26 & 0.03 & 2.98 \\
\hline Rule 10 & 0.91 & 1.26 & 0.03 & 2.92 \\
\hline
\end{tabular}

The table and chart depicts the values for the four metrics (confidence, lift, leverage and conviction) used for evaluating the association of products for the season September to December.

1. The confidence value greater than 0.90 for 10 rules implies that more than $90 \%$ of customers opting for cleaning_soaps, candles, tooth brushes \& tooth paste, bathing soaps and shampoos are certain to spend for Mosquito Killers.

2. The lift values greater than 1.25 implies that the interesting products are highly dependent closely knit together and their occurrences are highly dependent on the occurrence of Mosquito Killers.

3. The leverage value closer to 0 is an ample indication that the independence of interesting products and Mosquito Killers are almost negligible.

4. The conviction metric indicates that the customers wishing not to buy Mosquito Killers invariably choose not to buy the interesting products of the season.

\subsubsection{Interpretation}

The season emcompassing the months from September to December has seen a surge in the sale of Mosquito Killers along with other products of interest.

The increased sale of Mosquito Killers comes at the backdrop of Dengue fever that spread havoc in the season. It created fear in the minds of the people and they inturn resorted to Mosquito repellant products as a safety measure. As the months mark the torrential rainy season for the state of Tamil Nadu, it proved conducive climate for the inflation of mosquitos. Brands of all variety of mosquito repellants were moving well in the retail market.

The other surprise inclusion in the wish list of the customers happens to be the Candles as the product had seen an extended sale from the previous season(May to August) to the current season(September to December) due to the persistence of the power crisis in the state.

The other products noteworthy of the season are cleaning soaps, tooth brush and paste, bathing soaps and shampoos, which are as expected required for daily rudiments of the people.

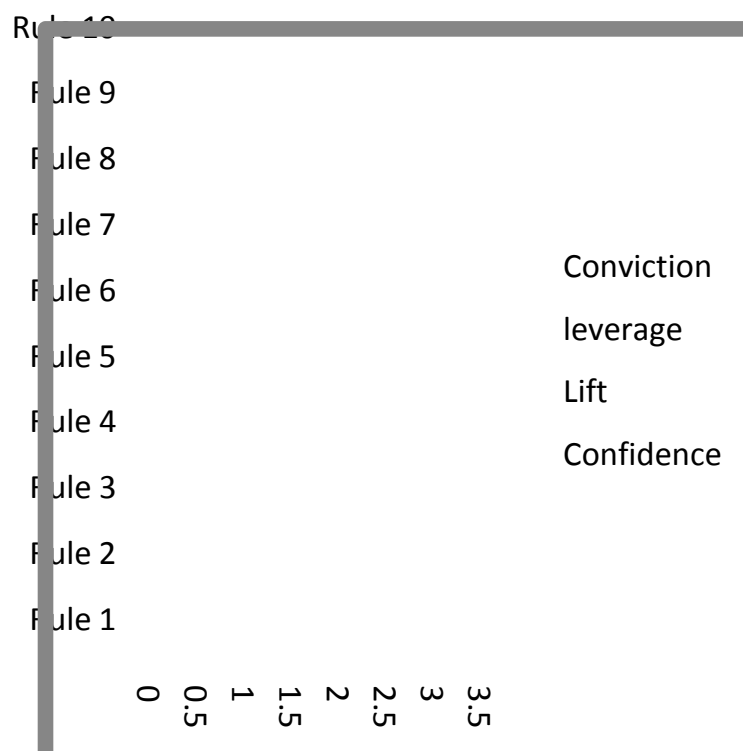

Fig 3: Association Metrics Chart for the Season September to December

\section{CONCLUSION}

An adage saying "The product for all seasons" is just a marketing gimmick and this myth is busted in this dissertation. There can't be a product ruling the roost round the year all the time. As every day throws up new problems and challenges for the people, it inadvertently creates an impact on the retail market. India boasts many seasons and each season is very transient in nature. So does the likes and dislikes of the customers. The retail market should stay alive to the possibilities and challenges that every season brings with it, in order to thrive in a cut-throat competition that prevail. The retail companies find it difficult to retain the customer loyalty more than so in winning their confidence at the first place. This study provides ample evidence that seasons drive the product sale and each season is exhibited in manifold and diverse attributes like festivals, social problems, economic constraints, climatic changes, etc.

In the current scenario the temporal trading of retail products has become inevitable and the companies should have an understanding of "what products for what season?". This mantra will help retail market outlets to have an insight about the most sought after products for every season.

The following conclusions were specifically drawn from this dissertation work that backs the theory that seasons are the reasons for the sale of a product.

- The festival seasons play a vital role in boosting a product sale as can be seen in this study for the season May-August, whereby there was a surge in the sale of Masala items.

- The climatic seasons are a big factor not to be overlooked as depicted in the season January-April, when the sales of juice items soared high in dry weather conditions.

- The seasons defined by socio-economic problems, mandate the profuse purchase of certain products. It was evident from the study that the onset of Dengue fever influenced the increased sale of Mosquito repellents for the season September-December. 
- Political factors also have an implicit bearing on the pulse of retail market as the power shortage crisis led to a dramatic increase in the purchase of candles, which in other cases would not have topped the customer's mustbuy list.

\section{RECOMMENDATIONS}

In wake of the outcome of the study, it is imperative that companies possess season oriented knowledge for marketing their products.

- It is highly recommended that the products for the season be analysed beforehand on the day-to-day basis and those products are exhibited at the forefront of their outlet to provide a prominent view of those products for an easy access of customers.

- The newly added customer base should be retained for the continued success of business. This can be achieved by providing value-additions to the products that they buy. For instance,

- Customers can be acquainted with the amount of calories the products being bought carries.

- Weight machines can be installed as many customers are fitness savvy.

- Small play stations can be set up for the parents can leave their child to play, so that they can purchase the products leisurely.

- A free product given away with other products is a time tested strategy. But an astute business man should choose the right products given free. The products that are best for the upcoming season should be identified and be given free. This strategy would act as a remainder for the customers to revisit shop when the season arrives.

\section{SUGGESTED FUTURE RESEARCH}

- This research was carried out exclusively for temporal analysis of association of products in retail market. This work focussed on data pertaining to a single locality. So the research can be extended by including the spatial dimensions as well. As seasons are locality based and changes from one place to another place, it is pertinent that spatial factors are weighed in to predict the best products for a given season.

- The mining is done for a season stretching for a period of 3 months. It can be taken to a coarse level by analysing it for a month or week or day to day basis. This may provide an in-depth knowledge of association of products

\section{ACKNOWLEDGMENTS}

I extend my profuse thanks to THE VICE CHANCELLOR, Sri Chandrashekarendra Saraswathi Viswa Maha Vidyalaya University, Kanchipuram, for having provided me with an opportunity to pursue M.Phil. in this divine Institution.
I express my whole hearted thanks to THE DEAN (FACULTY OF SCIENCE), Sri Chandrashekarendra Saraswathi Viswa Maha Vidyalaya University, Kanchipuram, for providing me the space and scope to carry out the dissertation work.

I render my gratitude to Dr. N.R.ANANTHA NARAYANAN, Head of the Department of Computer Science \& Applications, Sri Chandrasekharendra Saraswathi Viswa Mahavidyalaya University, Kanchipuram, for all his inspiration and support throughout the course of study. I acknowledge with profound thanks to MR. M. KANNAN, M.C.A., M.Phil., Assistant Professor, Department of Computer Science \& Application, Sri Chandrasekharendra Saraswathi Viswa Mahavidyalaya University, Kanchipuram, for his valuable insights, guidance and perseverance for successful completion of this dissertation.

I also register my special thanks to ALL THE STAFF MEMBERS in the Department of Computer Science \& Application, Sri Chandrasekharendra Saraswathi Viswa Mahavidyalaya University, Kanchipuram, for their valuable suggestions and advices.

\section{REFERENCES}

[1] Paulo J. Azevedo1 and Al'ipio M. Jorge "Comparing Rule Measures for Predictive Association Rules"

[2] pinnaboyina, Dhulipalla, Radharani "Survey Methods on Measuring Minimum Threshold for Association Rules"

[3] Maike Krause-Traudes, Simon Scheider, Stefan Rüping and Harald Meßner, "Spatial data mining for retail sales forecasting “

[4] Mu-Chen Chena, Ai-Lun Chiub, Hsu-Hwa Chang, "Mining changes in customer behaviour in retail marketing"

[5] Nikolaos Katsaras, Paul Wolfson, Jean Kinsey, Ben Senauer, "A Segmentation Analysis of U.S. Grocery Shoppers"

[6] Kenneth L. Reed and Joseph K. Berry, "Spatial Modeling And Data Mining In Retail Customer Loyalty, Competition Analysis, Propensity to Defect and Ad Media Selection".

[7] Dr. M. Dhanabhakyam, Dr. M. Punithavalli, "A Survey on Data Mining Algorithm for Market Basket Analysis".

[8] Tom Brijs Gilbert Swinnen Koen Vanhoof Geert Wets, "Using Association Rules for Product Assortment Decisions: A Case Study"

[9] Sema Kurtulu, and Kemal Kurtulu, "Prospects, problems of Marketing Research and Data Mining in Turkey"

[10] Raorane A.A.1 Kulkarni R.V.2 and Jitkar B.D., "Association Rule - Extracting Knowledge Using Market Basket Analysis". 